\title{
Global soils and sediment transfers in the Anthropocene: Database meeting
}

\author{
Thomas Hoffmann 1 and Veerle Vanacker ${ }^{2}$ \\ 3rd GloSS workshop, Koblenz, Germany, 18-20 October 2018
}

\begin{abstract}
The PAGES Global Soil and Sediment transfers in the Anthropocene (GloSS) working group aims to build a comprehensive global database on soil and sediment transfers in the Anthropocene, to identify hotspots of soil erosion and sediment deposition in response to human impacts, and locate data-poor regions as strategic foci for future work (Fig. 1)
\end{abstract}

The third workshop of the GloSS working group was hosted by the Federal Institute of Hydrology (Koblenz) and supported by the UNESCO-IHP International Center for Water Resources and Global Change (ICWRGC). The workshop aimed to synthesize the results from the regional task forces, discuss progress on the GloSS database and identify ways to motivate the GloSS members and the broader scientific community working with human impacts on soils and sediments to contribute to the compilation of the GloSS database. A total of 19 participants from different disciplines (geomorphology, geology, soil science, ecology, (paleo)limnology, and hydrology) and 10 countries from four continents contributed to the workshop.

The first day was dedicated to reports by the regional taskforce leaders that highlighted the progress of the regional working groups in terms of data compilation. The keynotes were given by Rajiv Sinha and
Sohini Bhattacharjee (Indian Institute of Technology, Kanpur, India), Juan Restrepo (EAFIT, University of Medellin, Colombia), Duncan Cook (Australian Catholic University, Melbourne), Allan James (University of South Carolina, USA), Dongfeng Li (National University of Singapore), Aleksey Sidorchuk (Moscow State University, Russia), and Gert Verstreaten (Leuven University, Belgium). Stephan Dietrich (ICWRGC, Germany) gave a presentation of the global GEMStat water quality database (gemstat.org), which is hosted at the ICWRGC in Koblenz, and Jean Phillipe Jenny (INRA Thonon, France) presented results from a European database on lake sediments.

\section{All keynotes presented a wealth of stud-} ies and data that provide the backbone for the GloSS database. However, it was noted by the keynote speakers that the focus of the GloSS working group on the full sediment pathway including hillslope and river systems (channels and floodplains), as well as lakes and deltas, is a major challenge (obstacle) to the compilation of the database. In contrast to other databases that have been compiled by the PAGES community, GloSS deals with various sedimentological archives and proxies over various temporal and spatial scales, with varying sensitivity to human disturbances. It was further noted that colleagues from the scientific community

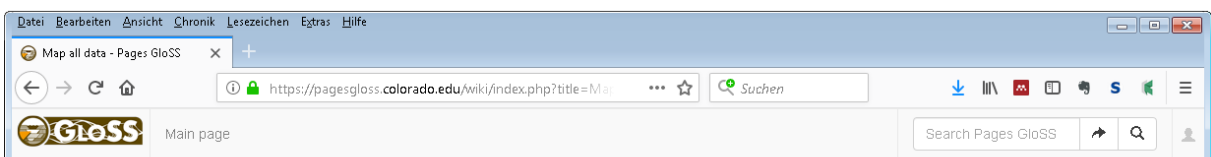

\section{Locations of all data}

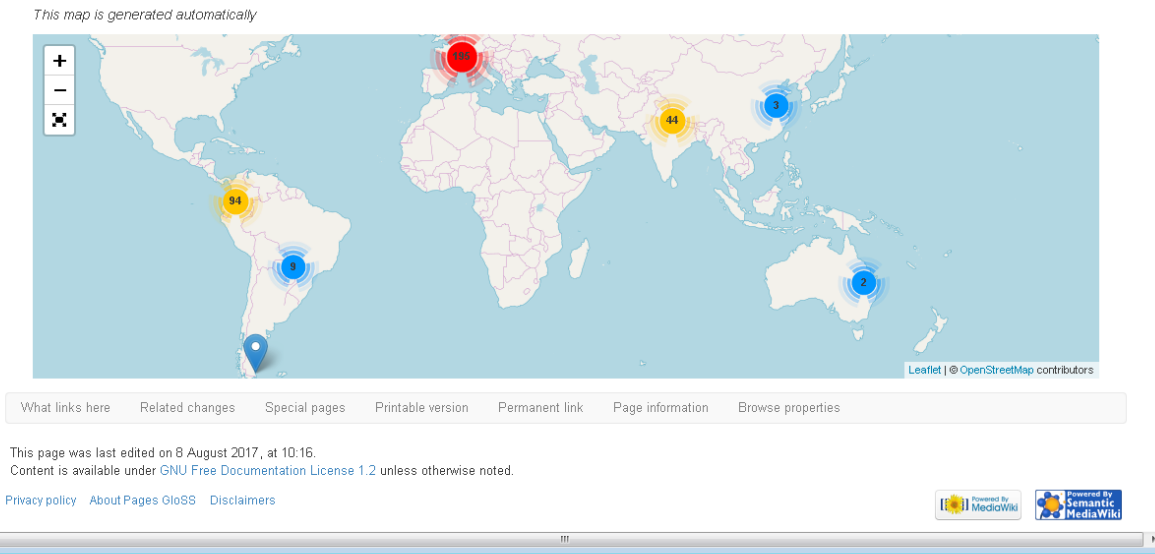

Figure 1: Screenshot of the GloSS wiki. The colored points indicate the number of datasets entered in the wiki as of 20 March 2019. The wiki is an open platform to enter data on past and present soil and sediment transfer. For more information see: pagesgloss.colorado.edu/wiki.

hesitate to contribute their data to the GloSS community if the benefit is not fully clarified.

During the second day, participants discussed the major shortcomings of the GloSS database and developed a strategy to increase the number of contributions from the scientific community to the GloSS working group. First, the strategy includes a statement on the publication policy of the GloSS working group, indicating that all publications derived from the GloSS working group results and the GloSS database should be published by the key authors and the GloSS consortium. Each scientist who provides information and data that support the population of the database will be a part of the GloSS consortium. Second, the strategy includes the compilation of a special issue in the journal Anthropocene. The special issue will include a mixture of i) regional synthesis papers that highlight the specific histories of human disturbance on soils and sediments on various continents, ii) large-scale/global compilations, and iii) parameter-specific databases that are of relevance for the GloSS community. The special issue will be completed by a paper on the conceptual framework of the GloSS database with a focus on the global synthesis.

The third day was dedicated to a city field trip along the Rhine River in Koblenz. Participants learned about the long-term history of soil erosion and sediment transport in the Rhine basin and the present-day sediment issues related to the management of the waterways in Germany. One focus was on the sediment-monitoring activities of the Federal Institute of Hydrology and the Water and Shipping Authority in Germany and the sediment budget analysis of the Rhine, which highlights the functioning of the heavily exploited Rhine waterway in the Anthropocene.

This group officially ended as a PAGES working group in 2018, but it is still active. Find it here: pastglobalchanges.org/ini/wg/former/ gloss/intro.

\section{AFFILIATIONS}

${ }^{1}$ German Federal Institute for Hydrology, Koblenz, Germany

${ }^{2}$ Earth and Life Institute, Catholic University of Louvain, Belgium

\section{CONTACT}

Thomas Hoffmann: Thomas.Hoffmann@bafg.de 